\title{
Experimental Study on Mechanical Characteristics of Jatropha Seeds
}

\author{
Z.J. WU ${ }^{1}$, B. WANG ${ }^{1} \&{ }^{*}$ L.H. ZHANG ${ }^{1}$
}

${ }^{1}$ College of Mechanical and Electrical Engineering, Sichuan Agricultural University. Ya'an, China.

KEYWORD: Jatropha seeds; Moisture Content; Loading speed; Loading direction; Mechanical characteristics;

ABSTRACT: [Objective] Recently, the interest in jatropha seeds has increased due to its high oil content. In order to study the mechanical characteristics of jatropha seeds, in this study, single factor tests, orthogonal tests were used. [Methods] Experimental factors were moisture content (MC) $(7.11 \% \sim 39.23 \%)$, loading speed(LS) $(5 \sim 40 \mathrm{~mm} / \mathrm{min})$ and loading direction(LD) $(\mathrm{X}, \mathrm{Y}, \mathrm{Z})$ while investigated responses were shell-breaking force(SBF), shell-breaking deformation(SBD), energy consumption(EC) and comprehensive evaluation(CE) The order of strength of the factors affecting the loading process and the best combination of the experimental factors when pressing jatropha seeds were determined to obtain through optimizing operating conditions. [Results] The orthogonal test and variance analysis demonstrated that the primary factor influencing the shell-breaking process was LD, followed the LS and MC. The best values of factors were found to be LS of 17.48 $\mathrm{mm} / \mathrm{min}$ with LD of $\mathrm{Y}$ for the MC of $15.44 \%$ and LS of $5 \mathrm{~mm} / \mathrm{min}$ with LD of X for the MC of $15.75 \%$ and the $\mathrm{CE}$ are obtained at 0.807 for $\mathrm{Y}$ and 0.603 for $\mathrm{X}$, respectively. [Conclusion] This study provides a theoretical basis for further study on equipment and technology for jatropha seeds.

\section{INTRODUCTION}

The energy sector is a main reason of man-made greenhouse gas emissions, therefore, to reach a projected target of $80 \%$ reduction in gas emissions by 2050 will put pressure on existing energy systems ${ }^{[1]}$.

Recently, there is a need therefore to explore sources of renewable energy that are viable and able to fulfill human energy demands and contribute towards a sustainable development economy. Jatropha curcas or jatropha is a small tree with a smooth grey bark which normally grows to a height of 3-5 m or of 8-10 m under suitable environment. It is recognized worldwide as a species which could most likely to alternative to fossil and become the future energy and its seeds oil content is around $30 \%{ }^{[2-7]}$. The modified jatropha seeds soil can be applied to a variety of diesel engines, and its performance meets European II emission standards in many key technologies. It is a promising fuel with technical, socio-economic and environmental benefits ${ }^{[8]}$. In addition, many of recent research papers has provided perspectives of jatropha biodiesel program in many countries such as $\mathrm{UK}^{[9]}$, Thailand[10], India ${ }^{[11]}$ and China ${ }^{[12]}$, et al. In this condition, jatropha curcas production has increased immensely in the past years due to the demand for biodiesel as an alternative fuel. It is estimated that by 2015 the global cultivated area of J. curcas will be around 12.8 million hectares ${ }^{[13]}$. Therefore, a good use of Jatropha seeds provides not only a solution to environmental pollution, it also could improve the development of renewable energy.

When the jatropha seeds arrive for oil extraction, the following procedures are conducted: dehulling, shelling(separating nut shell from kernel), drying, oil extraction and other. Designing the equipment for these processing, sorting, sizing and other post-harvesting of agricultural products requires information about their physical properties, especially mechanical properties ${ }^{[14,15]}$. Thus the design and manufacture of various processing equipment is necessary to collect the mechanical parameters based on jatropha seeds. Further more, the processing of jatropha seed could improve the economic value of Jatropha seed ${ }^{[16,17]}$ and the potential economic value expresses the number of people that could obtain an income per hectare Jatropha plantation ${ }^{[18]}$.

During the past few decades, many studies on the mechanical characteristics of varies seeds of fruit and vegetables, such as chestnut ${ }^{[19]}$, walnuts ${ }^{[20]}$, peanuts ${ }^{[21]}$, different mature period of jatropha seeds' mechanical characteristics was studied ${ }^{[22]}$. In this study, different temperatures were experimental factors but without considered the influence of loading speed and loading directions. Some physical and mechanical properties of jatropha seeds were also studied ${ }^{[23]}$, but it did not 
consider the impact of moisture content, loading directions and other factors on the mechanical properties. Although some studies have shown the importance of jatropha seeds and its physical mechanical properties have been revealed, there has been no study investigating the impact of moisture content, loading speed and loading directions on the mechanical properties.

\section{MATERIALS AND METHODS}

\section{Sample Preparation}

In the first step of experimental materials preparation of the seeds were cleaned from mechanical impurities and divided into several parts by length of the seeds with a calipers which 14 to $18 \mathrm{~mm}$ were used in the experiments. In the next step, in order to get samples with different moisture content, the non-treated seeds were put into a drying oven and kept at the temperature of 105C for hours when the drying changes in mass were not observed ${ }^{[24]}$, then recorded the mass as Mad with a balance. After this, the dried samples were soaked for 48 hours and delivered into 5 parts ( 120 seeds each part) before put into the drying oven in 60C again. During the second drying process, 1 part of 5 would be taken out interval 1 hours and recorded mass as Med All the samples were put into plastic bag in the refrigerator at $5 \mathrm{C}$ before pressing experiment. $\mathrm{MC}$ was calculate by the formula:

$$
M C=\frac{M e d-M c d}{M e d} \times 100 \%
$$

In this paper, the factor MC was calculated by formula (1) to be $7.11 \%$ to $39.23 \%$ w.b.

\section{Uniaxial Compression}

Compression of jatropha seeds was performed in a testing machine of crop operated at different MC, LS and LD. There are three loading directions $(X, Y, Z)$ for seeds compression in this study, which is shown in Fig.1. LS was regulated by PC linked to the rate control unit of the testing system. In this paper, LS was determined to be 5 to $40 \mathrm{~mm} / \mathrm{min}$ according to author's experience on common crop characteristics and previous studies. The jatropha seeds was placed stable on the platform, PC started recording data and drawing force-deformation curves once the plate touch the seeds and stopped when the seeds crack.

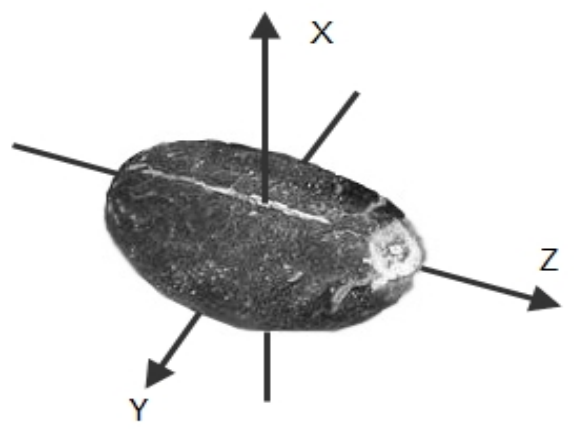

\section{Responses}

Fig. 1 Different modes of loading directions

Energy Consumption (EC) by the sample at rupture point and it was determined by calculating the area under the force-deformation curve by EXCEL software. EC was calculated by the follow formula:

$$
E C=\frac{1}{2} \sum_{i=1}^{n}\left[\left(F_{i}+F_{i+1}\right)\left(D_{i+1}-D_{i}\right)\right]
$$

Where EC is the energy consumption while the seeds rupture; Fi is the i-th time data of force during the pressing process acquisition by PC. Di is the $\mathrm{i}$-th time data of deformation during the pressing process acquisition by PC. 
CE: With a Comprehensive evaluation of membership, make the SBF, SBD, EC 3 indicators a comprehensive evaluation(CE) to jatropha seeds loading process, as formula(3):

$$
l_{X}=\frac{\left(c_{\max }-c_{i}\right)}{\left(c_{\max }-c_{\min }\right)}
$$

Where ci, cmin, cmax is the i time, the minimum, the maximum of index values, respectively.

CE was calculated as formula (4):

$$
C E=a \times l_{S B F}+b \times l_{S B D}+c \times l_{E C}
$$

Where li is membership and $a \sim c$ is the weights of each index. Priority to ensure minimal of three responses, in this paper $\mathrm{a}=0.5, \mathrm{~b}=0.3, \mathrm{c}=0.2$. According to the actual situation, $\mathrm{a} \sim \mathrm{c}$ can $b$ different, but they must satisfy the equation (5):

$$
a+b+c=1
$$

\section{Experiment Design and Optimization}

In this paper, RSM is used to investigate the main effect of process variables on comprehensive evaluation (CE) during pressing process of jatropha seeds, loading speed( LS), moisture content( MC) was selected as independent variables. Factor rang levels was determined by means of preliminary experiment which were considered as: MC in 5 levels $(7.11 \%-39.23 \%)$, LS in 7 level $(5-40 \mathrm{~mm} / \mathrm{min})$ and $\mathrm{LD}$ in 3 levels $(\mathrm{X}, \mathrm{Y}, \mathrm{Z})$.

Experiments were performed as single factor test and orthogonal test of two L9(34) tables including 18 experiments. Factor levels in orthogonal test is shown in table 1. For each treatment, 20 samples were randomly selected and the average values of all 20 experiments were reported.

Experimental data were analyzed using analysis of variance (ANOVA) and the means were separated at the 0.05 level applying Duncan multiple range which were conducted for fitting the models shown by formula (6) and to check the statistical significance of the models. The adequacy of the models were determined using model analysis, lack-of fit test and R2 (coefficient of determination) analysis (lack of fit $>0.1$; R2 $>0.95$ ). Software Matlab 2010a was used to fit the second order polynomial model and optimize the pressing process.

In the existing optimization of industrial process papers, several variables describing the quality characteristics and performs measures or response of the systems are usually to be optimized. In which some of these factors need to be minimized while others need to be maximized. In this paper, the quality characteristics is $\mathrm{CE}$ which need to be maximized and variable factors (LD, LS, MC) need to be find at this best point.

\section{RESULT AND ANALYSIS}

\section{Single Factor Test}

Effect of LD, MC and LS on LBF

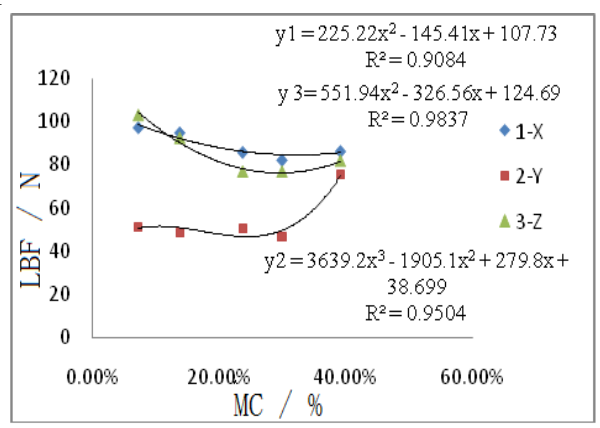

Fig. 3(a) 


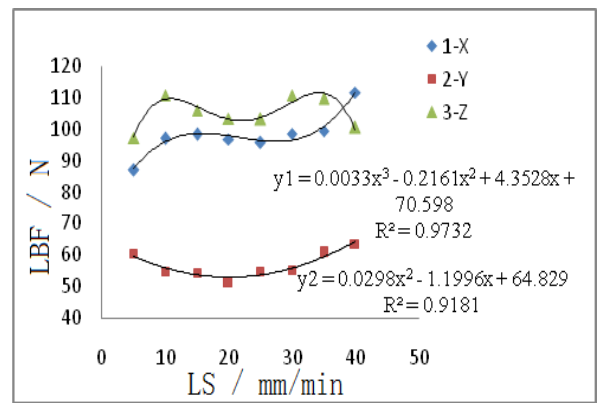

Fig. 3(b)

Fig.2 Effect of MC( 3a) and LS ( 3b) on LBF

According to Fig. 3 , the LBF find to decreased significantly (probability $\mathrm{P}<0.0 \quad 1$ ) in all LD as the MC increased from $7.11 \%$ to $39.23 \%$ w.b. However, the difference among LBF of jatropha seeds at the LS of $5 \mathrm{~mm} / \mathrm{min}$ to $40 \mathrm{~mm} / \mathrm{min}$ was found to be statistically insignificant for LD of Z and statistically week significant for both LD of X and Y. When jatropha seeds were loaded in the Z and $X$ orientation, respectively, require the maximum LBF $95-105 \mathrm{~N}$ and minimum LBF $50-55 \mathrm{~N}$. Compared with LD of X and Z, when jatropha seeds loaded in the LD of Y require substantially less force with the change of MC and LS. After the MC of $23.69 \%$, it required more force to crack jatropha seeds loaded in the LD of X but it is still lower than for those loaded in the LD of Y and Z. A similar MC-LBF curves trend was reported for sunflower seed ${ }^{[24]}$.

Effect of LD, MC and LS on LBD

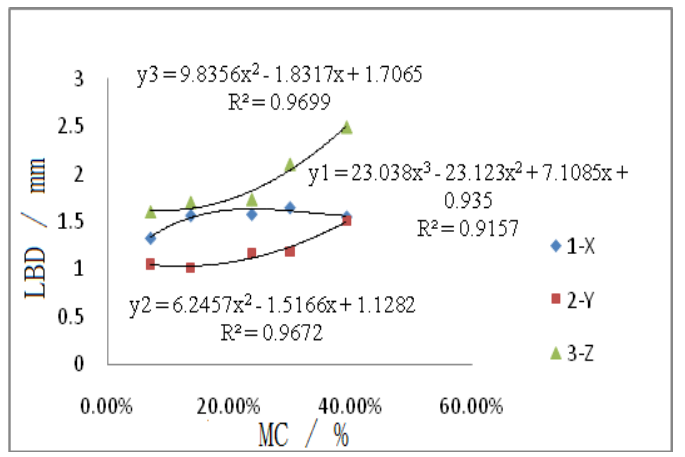

4(a)

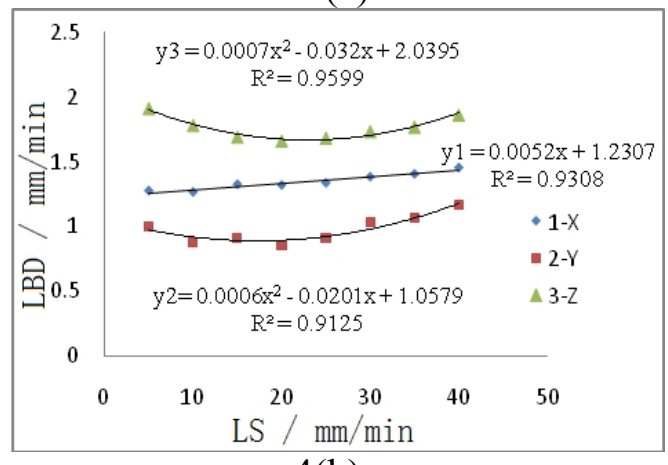

4(b)

Fig.3 Effect of MC( 4a) and LS ( 4b) on LBD

The LBD of the jatropha seeds at different levels of MC( $4 a)$ and LS(4b) for all LD of pressing are shown in Fig. 4. It can be observed that the LBD increase significantly (probability $\mathrm{P}<0.0 \quad 1$ ) as the MC increased for all the LD, substantially. This trend is attributed to a fact that when MC level is higher, the seeds become softer and tend to expand under loading and thus LBD became lager. The similar trend was reported on research of soybean in early years. ${ }^{[25]}$. However, the difference among LBD of jatropha seeds at the LS of $5 \mathrm{~mm} / \mathrm{min}$ to $40 \mathrm{~mm} / \mathrm{min}$ was found to be week significant for all LD levels. 
Effect of LD, MC and LS on EC
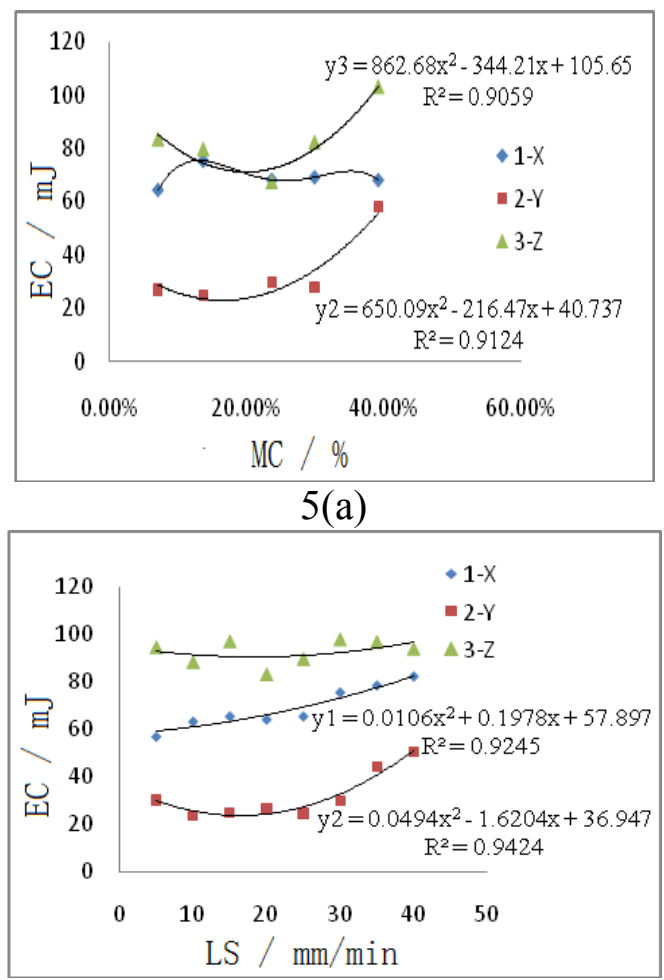

$5(\mathrm{~b})$

Fig.4 Effect of MC( $5 a$ ) and LS ( 5b) on EC

It is seen in Fig.5 showed the EC at rupture of jatropha seeds as a function of MC( $5 \mathrm{a})$ and LS( $5 b$ ) on all LD levels, the EC showed a significance(probability $\mathrm{P}<0.01$ ) changes as the MC increased for all the LD and LS for LD of $\mathrm{Y}$ and $\mathrm{Z}$, while a weak significance $(0.01<\mathrm{P}<0.05)$ for the increase of LS for LD of X. As seen in Fig.5, the EC showed a nonlinear relation to MC and LS, this is possibly due to the fact that EC is a response of both LBS and LBD. At low level of MC, the seed requires more LBF but its deformation was low. When MC level is higher, the LBF was low and the LBF was high. The same analysis was applied to changes of EC with different LS. The familiar trend was found at some other studies, such as pea pod ${ }^{[22]}$ and cumin seed ${ }^{[23]}$.

\section{ORTHOGONAL TEST}

Orthogonal Test Along X direction

Experimental design according to table $\mathrm{L}_{9}\left(3^{4}\right)$, a random combination of the test sequence, the different runs of test results are shown in Table 3.

Use range analysis and analysis of variance to analysis the weighted indicators obtained that: Impact weighted composite index of primary and secondary factors as A, B, the optimal combination of $\mathrm{A}_{2} \mathrm{~B}_{1}$. That is when the moisture content of $23.69 \%$, the loading speed of $5 \mathrm{~mm} /$ min, the highest composite weighted index. 
Table.1 Orthogonal Test Results Along X Direction

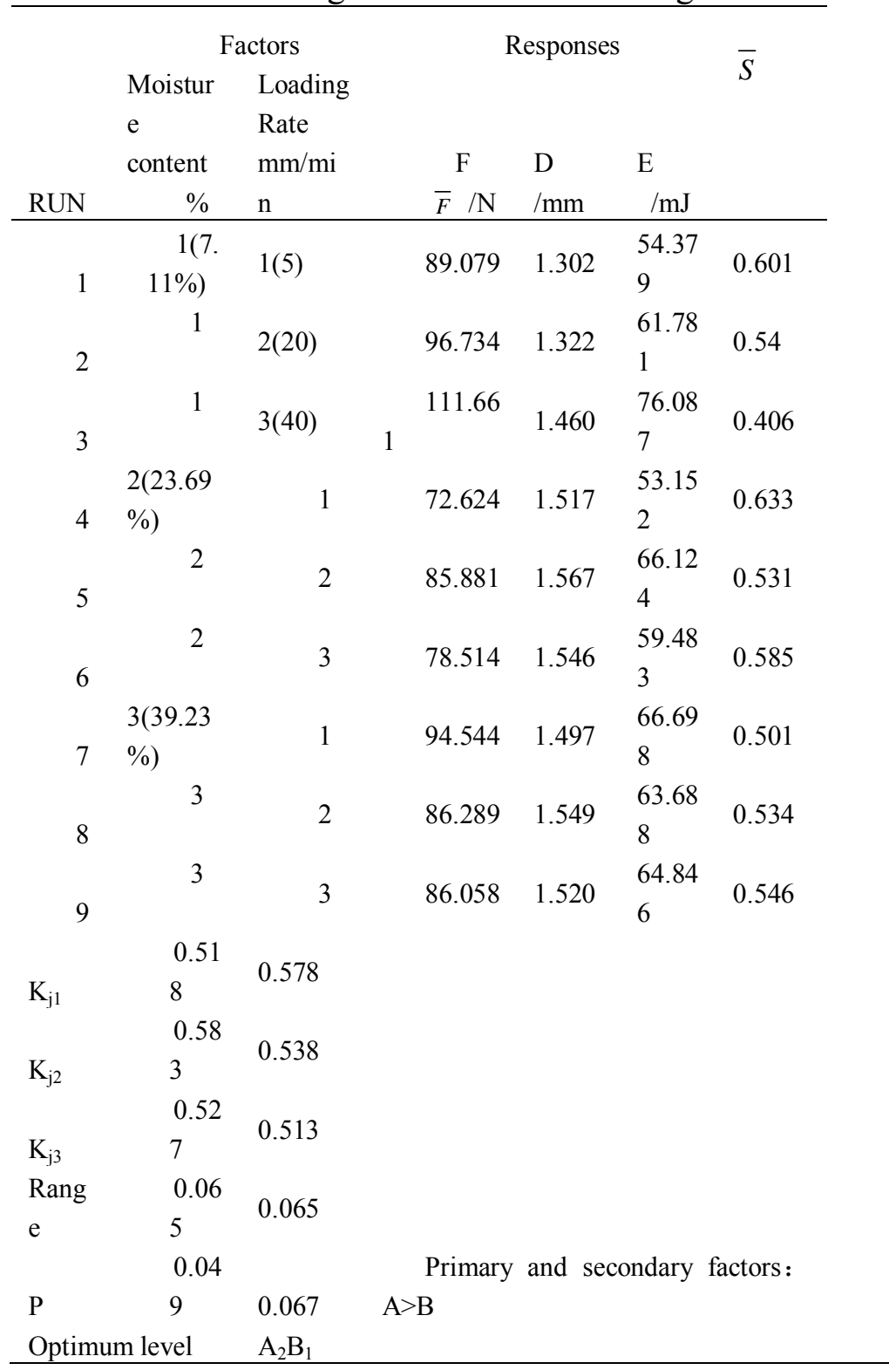

\section{Orthogonal Test Along Y direction}

Experimental arrangement is the same with loaded in the $\mathrm{X}$ direction, Orthogonal experiment results shown in Table 4.

Use range analysis and analysis of variance to analysis the weighted indicators obtained that: Impact weighted composite index of primary and secondary factors as A, B, the optimal combination of $\mathrm{A}_{1} \mathrm{~B}_{2}$. That is when the moisture content was $7.11 \%$, the loading speed of $20 \mathrm{~mm} /$ min, the highest composite weighted index.

Table 4 shows that: there's little difference between $\mathrm{K}_{\mathrm{A} 1}$ and $\mathrm{K}_{\mathrm{A} 2}$, but a big difference between the $\mathrm{K}_{\mathrm{A} 2}$ and $\mathrm{K}_{\mathrm{A} 3}$, indicating when the moisture content is less than $23.69 \%$, and its impact on the overall weighted index was not significant, once the moisture content reaches $39.23 \%$, its comprehensive weighted values significantly affected, which is in front of the univariate analysis results are consistent; the significance level of 0.05 , the loading speed on integrated weighted index was not significant, but the single response index analysis, loading rate of broken shell force, broken shell deformation analysis of variance $P$ values were $0.029,0.017$, indicating the force loading rate of broken shell, broken shell affect the amount of deformation is significant. 
Table. 2 Orthogonal Test Results Along Y Direction

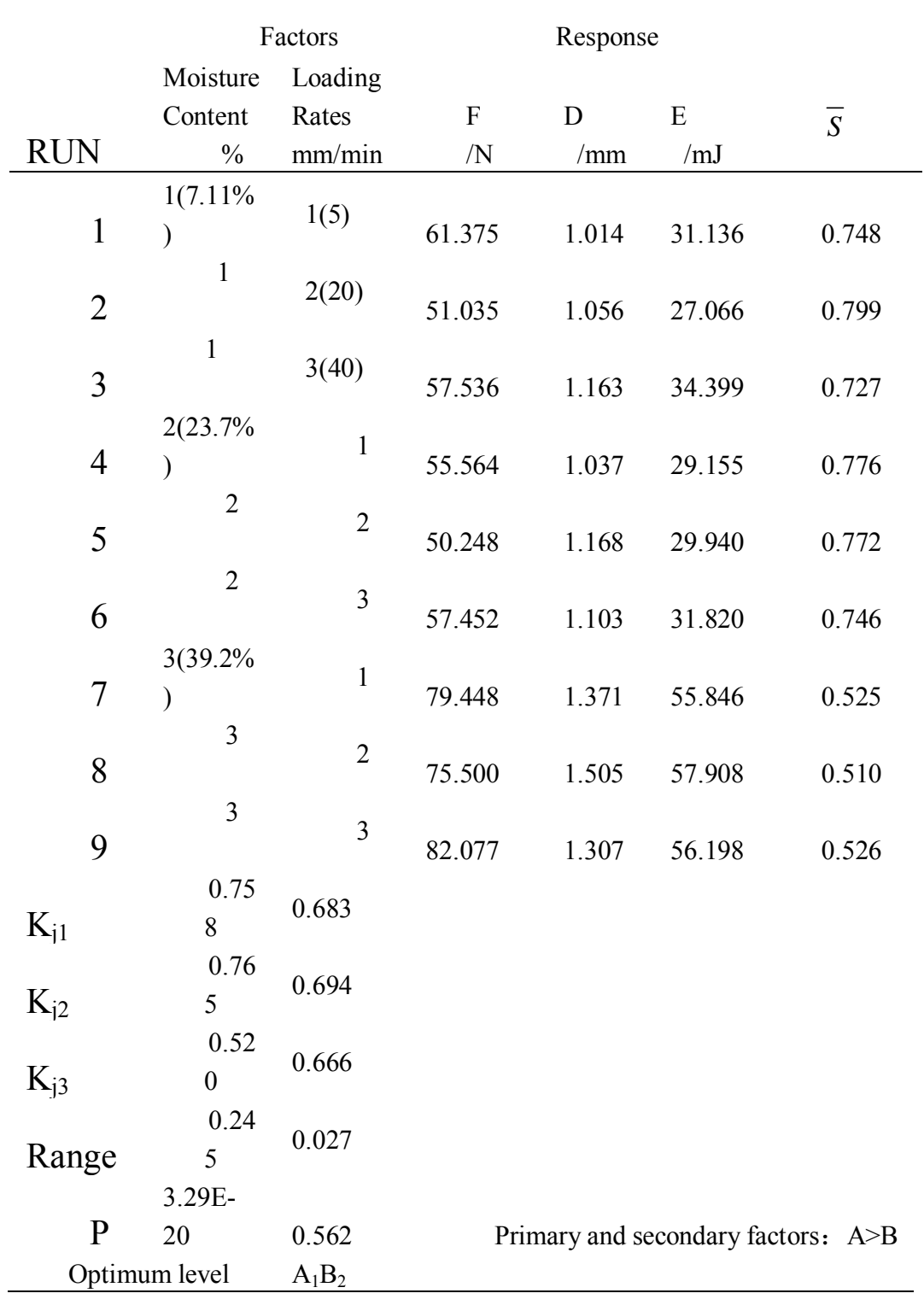

\section{CONCLUSION}

In this paper, the moisture content, loading rate and loading directions on the quality of jatropha seeds' shell breaking process was studied. The results revealed that the three factors influence on the loading process significantly.

Single factor tests showed: under various conditions, loaded from three directions $\mathrm{X}, \mathrm{Y}, \mathrm{Z}$, when loaded to break the shell along the $Y$ gets the minimum force, deformation and energy consumption. When loading at the speed of $20 \mathrm{~mm} / \mathrm{min}$ under $\mathrm{Y}, \mathrm{Z}$ directions, the moisture content effect on the force and, energy consumption is very significant. For $\mathrm{X}$ direction of force, the moisture content shows a weak significance on the energy consumption.For three directions of deformation, the moisture content shows a significant effect.

At the moisture content of $7.11 \%$, the loading speed effect on the force of $\mathrm{X}, \mathrm{Y}$ directions is very significant. On the force under the $Z$ direction it showed a week significant effect, and it showed a significant effect on the deformation under the direction of $X$ and $Z$. On the energy consumption, the loading speed showed a significant effect on $\mathrm{X}, \mathrm{Y}$ directions and a no significant on the $\mathrm{Z}$ direction. 
The Orthogonal test results showed that: when loading on the $\mathrm{X}$ direction, the best point is the moisture content of $23.69 \%$ with the loading speed of $5 \mathrm{~mm} / \mathrm{min}$; when loading on the $\mathrm{Y}$ direction, the best point is the moisture content of $7.11 \%$ with the loading speed of $20 \mathrm{~mm} / \mathrm{min}$.

This paper would provide a theoretical basis for the further study of jatropha seeds processing.

\section{ACKNOWLEDGEMENTS}

Corresponding Author: Lihua Zhang, Professor, Master Instructor. Research Direction: Machine and equipment for agriculture products processing. Email: zhanglihua69@126.com.

\section{REFERENCE}

[1] European Commission. Energy: roadmap 2050 2011:1-20.

[2] Contran N, Chessa L, Lubino M, Bellavite D. State-of-the-art of the Jatropha curcas productive chain: from sowing to biodiesel and by-products. Ind Crops Prod 2013;42:202-15.]

[3] Srividhya KP, Tamizharasan T, Jayaraj S, Muralledharan C. Characterization and gasification using Jatropha curcas seed cake. J Biofuels 2010;1:30-6.

[4] Abhilash PC, Srivastava P, Jamil S, Singh N. Revisited Jatropha curcas as an oil plant of multiple benefits: critical research needs and prospects for the future. Environ Sci Pollut Res 2011;18: 127-31.

[5] Openshaw K. A review of Jatropha curcas: an oil plant of unfulfilled promise. Biomass Bioenergy2000;19:1-15. ]

[6] Sujatha M,Reddy TP, Mahasi MJ. Role of biotechnological interventions in the improvement of castor(Ricinus communis L.) and Jatropha curcas L. Biotechnol Adv 2008; 26:424-435.

[7] Achten WMJ, Verchot L, Franken YJ, Mathijs E, Singh VP, Aerts R, et al. Jatropha bio-diesel production and use.BiomassBioenergy2008;32:1063-84.

[8] Sinha P, Pandey A. An evaluative report and challenges for fermentative biohydrogen production. Int J Hydrogen Energy 2011;36:7460-78.

[9] Carvalho CR, Clarindo WR, Praca MM, Araujo FS, Carels N (2008) Genome size, base composition and karyotype of Jatropha curcas L., an important biofuel plant. Plant Sci 174:613-61

[10] Iriwardhana M, Opathella GKC, Jha MK(2009). Bio-diesel: Initiatives, potential and prospects in Thailand: A Review. Energy Policy 37: 554-559.

[11] Bar H, Bhui DK, Sahoo GP, Sarkar P, De SP, Misra A (2009) Green synthesis of silver nanoparticles using latex of Jatropha curcas. Colloids Surf A Physicochem Eng Asp 339:134-139.

[12] Li Z, Lin BL, Zhao X, Sagisaka M, Shibazaki R. System approach for evaluating the potential yield and plantation of Jatropha curcas L. on aglobal scale.

[13] EnvironSciTechnol2010;44:2204-9. Contran N, Chessa L, Lubino M, Bellavite D. State-ofthe-art of the Jatropha curcas productive chain: from sowing to biodiesel and by-products. Ind Crops Prod 2013;42:202-15.

[14] Seyed M.A. Razavi, , B. Emadzadeh, A. Rafe, A. Mohammad Amini, Volume 81, Issue 1, July 2007, Pages 209-217, The physical properties of pistachio nut and its kernel as a function of moisture content and variety: Part I. Geometrical properties. Journal of Food Engineering.

[15] Sirisomboon P. Sirisomboon, P. Pornchaloeampong, T. Romphophak et al., 2007 P. Physical properties of green soybean: Criteria for sorting. Journal of Food Engineering, 79 (2007), pp. 1822.

[16] Zhongxin Li, Jun Yang, Liling Yang, et al. Walnut Exuviating Takes the Kind Craft and the Key Equipment[J]. Journal of Agricultural Mechanization Research. 2008(12): 27-29.

[17] Elmasry G, Radwan S, Elamir M, et al. Investigating the effect of moisture content on some properties of peanut by aid of digital image analysis[J]. Food and Bioproducts Processing. 2009, 87(4): 273-281.

[18] M. Nazari Galedar, S.s. Mohtasebi, A. Tabatabaeefar, et al. Mechanical behavior of pistachio nut and its kernel under compression loading[J]. Journal of Food Engineering. 2009, 95(3): 499504.

[19] Koya O A, Faborode M O. Mathematical Modelling of Palm Nut Cracking based on Hertz's Theory[J]. Biosystems Engineering. 2005, 91(4): 471-478. 
[20] Sirisomboon P, Kitchaiya P, Pholpho T, et al. Physical and mechanical properties of Jatropha curcas L. fruits, nuts and kernels[J]. Biosystems Engineering. 2007, 97(2): 201-207.

[21] Cheng Xian-li,Gao Lian-xing,Liu Ming-guo, et al. Experimental Study on Peanuts Mechanical Performance under Impacting Test[J]. Journal of Shenyang Agricultural University. 2009, 40(1): 111-113.

[22] D. Herak;G. Gurdil;A. Sedlacek;O. Dajbych;S. Simanjuntak. Energy demands for pressing Jatropha curcas L. seeds[J]. Biosystems Engineering. 2010, 106(4): 527-534.

[23] Kashaninejad, M., Mortazavi, A., Safekordi, A., \& Tabil, L. G. (2005). Some physical properties of pistachio (Pistachio vera L.) nut and its kernel. Journal of Food Engineering, 72(1), $30-38$.

[24] R. K. Gupta, S. K. Das. Fracture resistance of sunflower seed and kernel to compressive loading, J. Food Eng. 46 (2000)1-8.

[25] R. M. Paulsen. Fracture resistance of soybeans to compressive loading, Trans. ASAE 21(1978) 1210-1216.

[26] J. Khazaei, Determination of force required to pea pod harvesting and mechanical resistance to impact, Ph.D Thesis, Faculty of Biosystem Engineering, University of Tehran, Karaj, Iran, 2002.

[27] M. H. Saiedirad, A. Tabatabaeefar, M. Borghei. Effect of moisture content, seed size, loading rate and seed orientation on force and energy required for fracturing cumin seed under quasi-static loading, J. Food Eng. 86 (2008)565-572. 